international standards, to replace the malpractice of restraining patients who had become aggressive.

The establishment of several new departments has solved some of the problems of service provision but has also created pressure because of the need to staff these units. The problem was partially addressed through the employment of 50 new nursing staff and more than 50 new care assistants.

\section{The capacity-building programme}

The hospital recruited 23 new doctors, who signed contracts and started working as trainees in psychiatry. Five have gone on to pass the first part of the Arab Board examination in psychiatry.

An agreement was made to link to regional excellence centres for capacity-building programmes, which support study tours in neighbouring countries. A programme of twinning Libyan hospitals with other psychiatric hospitals in the region has now been running for over 6 months.

Visiting professors and trainers were invited back to the country, including expatriate Libyan mental health professionals. The World Health Organization has supported training within the hospitals. Short courses have been established both for general doctors and for the team working at the hospital, to bridge the gap in human resources.

In order to get psychiatrists from all over the country together, the hospital has supported the establishment of a professional organisation, the Libyan Psychiatric Association; previously psychiatrists came under the Libyan Neurology Association. Furthermore, the Libyan Board for Psychiatry Training is now in the process of establishment and official training in psychiatry is expected to begin in 2014.

\section{Introducing a rights-based approach to mental health practice}

The malpractice of administering electroconvulsive therapy (ECT) without anaesthesia was stopped and it is given now only with general anaesthesia. Guidelines on the use of seclusion and restraint have been drawn up. Seclusion rooms have been introduced, based on international standards, to replace physical restraints.

Patient complaints are now collected and reviewed by dedicated staff.

\section{A community-based approach to services}

Teams at the hospital supported the launch of the first psychiatric out-patient department at the Tripoli central hospital. Outreach services have been started to support local prisons, as well as centres for people with intellectual disabilities and a nursing home for elderly people.

In order to open up the hospitals to the community, a day care unit has been established. This is designed to provide services for in-patients; here, they can learn new skills away from the hospital culture. Other service users from the community together with family members will become involved too, thus bridging the former gulf between the community and the hospital.

\section{Conclusion}

All these reforms at the hospital are associated with a larger and more ambitious reform process in the national mental health system in Libya, which is supported by the World Health Organization in partnership with the Libyan Centres for Disease Control and Ministry of Health. This process was initiated in late 2011, and includes the introduction of capacity-building programmes for multidisciplinary professionals, initiating community mental health services, supporting mental health and launching advocacy and awareness programmes for mental health such as ongoing training for general practitioners, psychologists and social workers.

\title{
THEMATIC
} PAPER

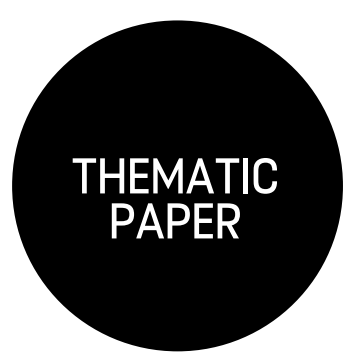

\section{CONFLICT AND MENTAL HEALTH IN NORTH AFRICA AND THE MIDDLE EAST Mental health in Syria}

\author{
Mohammed Abou-Saleh ${ }^{1}$ and Mamoun Mobayed ${ }^{2}$
}

'Chief Executive Officer, Naufar (Qatar Addiction Treatment and Rehabilitation Centre), Doha, Qatar; and Professor of Psychiatry, St George's, University of London, UK emailmabousal@sgulac.uk

2Senior Consultant Psychiatrist, Al-Aween Social Rehabilitation Centre, Doha, Qatar
This paper begins by outlining the nature of the present conflict in Syria. It goes on to describe the psychological consequences of this conflict and the present state of the mental health services in the country.

\section{The Syrian conflict}

Syria has been in a state of conflict for over 2 years. What started as a civil protest against decades of oppression and human rights violations by the Syrian regime rapidly escalated into a humanitarian and 
public health catastrophe. The brutal actions of the Syrian regime have continued since March 2011, with the United Nations (UN) reporting in January 2013 that there had been over 60000 people killed (including 4084 children, 3986 women, 1405 protesters killed under torture, plus an unknown number of soldiers) (Price et al, 2013a; updated as Price et al, 2013b, with an estimate of over 90000 people killed). There are more than 60000 people who are missing, over 200000 who have been arrested and over 137000 who have been critically injured or disabled. Two million people have been displaced, both within but especially outside the country, to camps in Jordan, Lebanon and Turkey, with little prospect of returning soon.

A delegation to Syria from the UN Office for the Coordination of Humanitarian Affairs found that $35 \%$ of hospitals, $10 \%$ of health centres and $40 \%$ of the country's ambulances had been severely damaged (Amos, 2013). In major cities such as Aleppo, Hama and Homs, the public health systems have collapsed: disease registration and vaccination programmes have stopped and many qualified doctors have fled the country. Only very basic health services exist in the refugee camps of Lebanon, Jordan and southern Turkey, and some camps have no health services at all. Journalists have reported children dying from exposure to cold and a lack of medical care for physical injuries caused by armed conflict (Coutts et al, 2013).

A crisis report from the United Nations Children's Fund (UNICEF), Syria's Children: A Lost Generation?, indicated that of the 4 million affected people inside Syria, almost 2 million are children, and of the 2 million who have been displaced outside the country, 800000 are children (UNICEF, 2013). Children have been exposed to grave human rights violations, including killing and maiming, sexual violence, torture, arbitrary detention, recruitment and use by armed forces and groups, and exposure to the explosive remnants of war. Basic infrastructure and public services are being systematically destroyed. Families are struggling to survive in increasingly desperate conditions. One in every five schools in Syria has been destroyed, damaged or converted into shelters for displaced families - disrupting schooling for hundreds of thousands of children (UNICEF, 2013).

There has been a tremendous amount of destruction; reports say that some towns and villages have been completely demolished, and the economic cost of the conflict has been estimated at hundreds of millions of dollars.

\section{The psychological consequences of the conflict}

There are no published studies on the impact of the conflict on mental health in Syria. A study by one the authors (Mobayed, in preparation) of a random sample of 228 Syrian men and women aged between 18 and 65 years, selected from two camps, who had been exposed to the conflict, reported prevalence rates of post-traumatic stress disorder (PTSD) across the camps from $36.3 \%$ to
61.9\%. Exposure to fighting and hostility and a history of trauma before the current conflict were the main predictors of current symptoms of PTSD.

The study also involved 129 Syrian children aged 10-16 years from two camps. The number of traumatic experiences related to conflict was positively correlated with PTSD symptoms, and the prevalence of PTSD among the children was higher than among adults, at $41.3-76.4 \%$.

A survey of 300 Syrian refugees in four camps in southern Turkey reported the prevalence rate of PTSD to be $61 \%$, morbid anxiety $53 \%$ and morbid depression 54\% (Marwa, 2012). These results are similar to the findings of studies of the mental health consequences of conflict in Palestine and Lebanon. For instance, a Lebanon study reported that, 20 years after the war, PTSD-related chronic diseases and physical symptoms were associated with a greater engagement in risk behaviours (Saab et al, 2003).

It was distressing to learn that the main psychiatric hospital of Ibn Khaldun in the suburb of Nayrab in the city of Aleppo was bombarded on 25 December 2012; patients fled and were abandoned to their fate. Some were subsequently killed by snipers, according to local reports (see http://www. youtube.com/watch?v=_ynVqQ2vhuU). The Dar al-Ajaza psychiatric hospital in the Old City has also been bombarded but remains in operation because of the dedication of its staff. The ancient mental hospital Bimaristan Argun dating to the 14th century AD, has also been damaged (see http:// archaeolife.blogspot.com/2012/10/destruction-ofbimaristan-arghun-of.html).

\section{Mental health services in Syria}

Syria is considered to be a lower middle-income country. It has predominantly residential mental health services, comprising two mental hospitals in Damascus and Aleppo (1200 beds in total). In addition, there is an addiction treatment centre in Damascus (30 beds), mental health departments in two military general hospitals and a psychiatric ward (with 12 beds) at Damascus University Hospital. Syria has two small private hospitals (Assalman et al, 2008). Community mental health services are rudimentary, comprising clinics in major cities, with the majority being private clinics. The number of mental health professionals is low (1 per 100000 population), with very few specialists in child and adolescent mental health and other subspecialties.

Because there have been both massive destruction of health service infrastructure, including mental health services, and an increase in the prevalence of mental health problems as a result of the conflict, it is expected that mental health conditions will overwhelm services. In the future, most Syrians with mental health problems can expect no treatment or care.

\section{Discussion and conclusion}

The conflict in Syria, which is now in its third year, is almost unprecedented in the magnitude of 
humanitarian and public health catastrophe. The Lancet stated in an editorial:

As if the direct effects of military force on Syrians were not enough, there has also been a full-scale assault on the health infrastructure. Even if Syrians are able to reach health facilities, which they often cannot because of ground fighting and erratic and unsafe transport, government forces have targeted health-care facilities, health workers, and patients intentionally, as described by independent observers such as Physicians for Human Rights, Amnesty International, and Médecins Sans Frontières. (Coutts et al, 2013)

It is very disturbing that the world has been witness to these atrocities but it has done so little to intervene. The Lancet rightly also stated:

A disturbing feature of modern conflicts and, indeed, the Arab uprisings, has been the flagrant disregard for the Geneva Conventions, including targeting of civilians, persecution of health workers, and attacks on hospitals, alongside the failure of the UN system to prevent these violations. The medical community may feel hopelessness in the face of these seemingly intractable situations. But there is much that it can do to monitor, report, and prevent the impact of conflict on the health of populations, as well as condemning attacks on civilians and breaches of medical neutrality. (Coutts et al, 2013)

The World Health Organization (WHO), as well as professional and humanitarian organisations, including non-governmental organisations (NGOs), has called attention to these challenges. The World Federation for Mental Health (WFMH), a global NGO, issued a statement in March 2013 on the mental health consequences of the complex emergency in Syria and made a call for action. Of major concern to the WFMH is that combatants on both sides of the conflict are generally ignoring the mental health consequences of the hardship and trauma created by violence and disruption. The WFMH called urgently for all parties involved, including the Syrian government and those contributing aid to support the conflict, to respond specifically to these issues and to consider the serious immediate and long-term mental health consequences of continuing armed conflict. Major humanitarian organisations that traditionally have not prioritised mental health should provide the means to support established organisations like the WFMH to expand training and services according to the Guidelines on Mental Health and Psychosocial Support in Emergency Settings produced by the Inter-Agency Standing Committee (2007).

The overriding priority for mental health in Syria now is to determine the mental health burden and consequent service response needs in relation to the conflict. A recent study in postconflict Libya estimated the number of cases of severe PTSD and depression and related healthservice requirements from the 2011 conflict there, and recommended mental health service targets (Charlson et al, 2012). When the conflict in Syria ends, what remains of the mental health services will be grossly insufficient to meet the predicted care needs. We call on national regional and international organisations to address these needs as part of the reconstruction of health services and to assist in providing skilled human resources for the suffering people of Syria.

\section{References}

Amos, V. (2013) Under-Secretary-General for Humanitarian Affairs and Emergency Relief Coordinator, Security Council Briefing on Syria. Available at https://docs.unocha.org/sites/dms/Documents/ USG $\% 20$ Amos $\% 20$ Security $\% 20$ Council $\% 20$ on $\% 20$ Syria $\% 20$ 18\% 20April\% 202013\% 20CAD.pdf (accessed June 2013).

Assalman, I., Alkhalil, M. \& Curtice, M. (2008) Mental health in the Syrian Arab Republic. International Psychiatry, 5, 64-66.

Charlson, F. J., Steel, Z., Degenhardt, L., et al (2012) Predicting the impact of the 2011 conflict in Libya on population mental health: PTSD and depression prevalence and mental health service requirements. PLoS One, 7, e40593.

Coutts, A., McKee, M. \& Stuckler, D. (2013) The emerging Syrian health crisis. Lancet, 381, e6-7.

Inter-Agency Standing Committee (IASC) (2007) Guidelines on Mental Health and Psychosocial Support in Emergency Settings. Available at http://www.who.int/mental health/emergencies/ guidelines_iasc_mental_health_psychosocial_june_2007.pdf (accessed June 2013).

Marwa, M. K. (2012) Psychosocial sequels of Syrian revolution, Abstract presented at the Pan Arab Psychiatric Conference, Dubai, December. Available at http://www.papc2012.com/program day_2.html (accessed June 2013).

Price, M., Klingner, J. \& Ball, P. (2013a) Preliminary Statistical Analysis of Documentation of Killings in the Syrian Arab Republic. United Nations Office of the High Commissioner for Human Rights (OHCHR). Available at http://www.ohchr.org/Documents/Countries/ SY/PreliminaryStatAnalysisKillingsInSyria.pdf (accessed June 2013).

Price, M., Klingner, J., Qtiesh, A., et al (2013b) Updated Statistical Analysis of Documentation of Killings in the Syrian Arab Republic. United Nations Office of the High Commissioner for Human Rights (OHCHR). Available at http://www.ohchr.org/Documents/Countries/ SY/HRDAG-Updated-SY-report.pdf (accessed June 2013).

Saab, B. R., Chaaya, M., Doumit, M., et al (2003) Predictors of psychological distress in Lebanese hostages of war. Social Science and Medicine, 57, 1249-1257.

UNICEF (2013) Syria's Children: A Lost Generation? Crisis Report March 2011 - March 2013. Available at http://www.unicef.org/ infobycountry/files/Syria_2yr_Report.pdf (accessed June 2013).

World Federation for Mental Health (2013) WFMH statement on the mental health consequences of the conflict in Syria: a call for urgent action. Available at http://www.wfmh.com/00policyrights. htm\#CONSEQUENCES_OF_THE_CONFLICT_IN_SYRIA:_A_CALL_ FOR_URGENT_ACTION (accessed June 2013). 